\title{
Gun Tube Rifling Electrochemical Machining Cathode Design and Experiment Study
}

\author{
Tang Lin* \\ *Corresponding author \\ School of Mechatronic Engineering \\ Xi'an Technological University \\ Xi'an, China \\ e-mail: tang_lin168@126.com \\ Fan Zhijian \\ School of Mechatronic Engineering \\ Xi'an Technological University \\ Xi'an, China \\ e-mail: zhijian_fan@163.com
}

\author{
Gan Weimin \\ School of Mechatronics Engineering \\ Changzhou Institute of Technology \\ Chang Zhou, China \\ e-mail: ganwm@czu.cn
}

\begin{abstract}
Mixed rifle has the merit of improving the accuracy, range, and lifetime of gun tube. Due to the large caliber, the deep helix groove, and the long barrel of largecaliber cannon artillery, the traditional way is a complex, reiterative and time consuming process to design an effective cathode for electrochemical machining of rifle. In this paper, in order to improve the efficiency of electrochemical machining and reduce the interference between the rifles and the cathode working teeth, mathematical models are proposed. The computer aided ECM cathode design is described and the three-dimensional cathode body model was set up with UG software. According to the model parameters, the gun tube rifle cathode is designed and manufactured via electrochemical theories, and the experiment was carried out. The experimental results are harmony with the theoretical rifle. It is demonstrated that the computer-aided design for ECM cathode can improve the design precision of cathode, reduce the experimental workload, and shorten the cathode design cycle.
\end{abstract}

Keywords-electrochemical machining (ECM); gun tube; mixed rifle; cathode design; computer aided design

\section{INTRODUCTION}

Nowadays, electrochemical machining (ECM) is becoming one of the important non-traditional machining technologies due to its merit of high efficiency, perfect surface quality, stress free and no tool wear. Therefore, ECM can be widely used in machining heat-resistant, highstrength, complex shapes, and difficult-to-cut materials in mould, military and aerospace industries, such as turbine parts, high-compression engines and gun tube rifling, which would otherwise be difficult to process through conventional machining technologies [1-2]. Many scholars used parameters optimization to improve ECM performance [3-6]. Lu et al. monitored the inter electrode gap of ECM with six-axis force sensor during the experimental investigation [7]. Wang and Zhu used the multiple electrodes machining micro-holes array in ECM [8]. Kozak et al. used the spherical electrodes to machining sculptured surface [9-10]. The electrolyte flow field, experiments, ECM assisted by low frequency vibrations and pulsed electrochemical machining were investigated [11-13]. $\mathrm{Xu}$ et al. adopted the rotary tool-cathode to machining contour evolution with NC-electrochemical machine tool [14]. Purcar et al. carried out advanced CAD integrated method of 3D ECM computer simulations [15]. There are many scholars did the electrochemical shaping simulation, convergence analysis for cathode design of aero engine blades, mathematical models, boundary element, multiphysics simulation of compressor blade, gas turbine blade cooling hole FEM simulation and the nonstationar ECM processes simulation research to improve ECM quality [16-17]. ECM technology can be application in inner surface polishing, machining spiral internal and ECM rifling [18].

Although research institutes and researchers have already initiated some research in gun tube rifling machining, few papers are concerned with electrochemical machining mixed rifling cathode design, especially in the process of moving electrochemical machining cathode Further researches are still needed to make this technology applicable in real production.

ECM method is the best candidate for manufacturing gun tube rifling. The aim of this paper is to study the electrochemical machining of the inside mixed rifling of a special cannon-pipe. The mathematics and geometry model of cathode are set up, manufactured and the experiments are carried out in this research. Our results demonstrated that the computer-aided design for tool cathode feed from three sides and simulation of machining can improve the design precision of cathode, reduce the experimental workload, and shorten the cathode design cycle.

\section{MATHEMATICAL MODEL OF ECM CATHODE}

Wherever Times is specified, Times Roman or Times New Roman may be used. If neither is available on your word processor, please use the font closest in appearance to Times. Avoid using bit-mapped fonts if possible. TrueType 1 or Open Type fonts are preferred. Please embed symbol fonts, as well, for math, etc. 
There is a growing industrial demand to increase the performance of processes with the development of new metal alloy materials. Usually, the designing of ECM cathode needs huge human resources. In order to ensure high efficiency and low cost process, building a appropriate model that describing the physics of the ECM process is necessary.

In order to make the simulation system more accurate and creditable, we should build up precise mathematical model. The object of manufacture is gun tube rifle. The equation of the ballistic trajectory is as follows:

$$
y=\frac{x^{2}}{p}
$$

Where $x$ and $y$ are the axis length of the cannon pipe and the perimeter of the gun tube, $\mathrm{p}$ is a constant parameter. The differential coefficient to $y$, so that:

$$
y^{\prime}=\frac{2 x}{p}
$$

That is to say: $y^{\prime}=\tan \varphi$

Where $\varphi$ is the included angle of $v_{x}$ and $v_{y}, v_{x}$ and $v_{y}$ are the speeds of $\mathrm{X}$ and $\mathrm{Y}$ direction, so that:

$$
\tan \varphi=\frac{v_{\mathrm{y}}}{v_{\mathrm{x}}}
$$

First of all, in order to reduce intervene between cathode and gun tube rifle, we adopt the methods of cutting $\theta$ to reduce the width of the small tooth $b_{\mathrm{c}}$, so that:

$$
B=B_{\mathrm{c}}+2 \Delta_{\mathrm{c}}
$$

The profile of the gun tube rifle and 3D cathode are shown in Fig. 1. In the figure.the main parameters are as follows:

$B_{\mathrm{a}}$ : The width of cannon rifle

$h_{\mathrm{a}}$ : The deepth of cannon rifle

$B_{\mathrm{c}}$ : The width of the big tooth

$b_{\mathrm{c}}$ : The width of the small tooth

$L_{\mathrm{c}}$ : The length of the work tooth

$\Delta_{\mathrm{c}}$ : The gaps between rifle and cathode flank

$\Delta_{0}$ : The gaps between rifle and cathode crest

$\alpha$ : Half-angle of the cathode tooth

$\beta$ : Half-taper angle of the cathode tooth

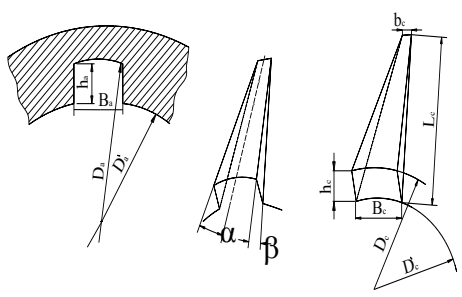

Figure 1.

Parameters of tube rifle and cathode tooth.
The deepth of cannon pipe rifle can be calculated from the following equation:

$$
H=L_{\mathrm{c}} \tan \beta+\Delta_{0}
$$

According to designing the exit tangle of the cannon pipe rifle, the cathode work tooth angle is $\varphi_{1}$, the inlet angle of the cannon is $\varphi_{0}$, then into the accelerando portion the angle is grade change from $\varphi_{x}$. When machining, the rifle angle is not agreement with the work tooth angle, the width of the rifle will be more wider than the size of design, we called it "interference". The dilated width can be also calculated from the following equation:

$$
\Delta_{\mathrm{B}}=B_{\mathrm{x}}-b_{\mathrm{c}}
$$

In order to reduce interference, we shorten the cathode teeth's length, it must cut into $\theta$, the cathode tooth in three portions movement sketch map is shown in Figure2.

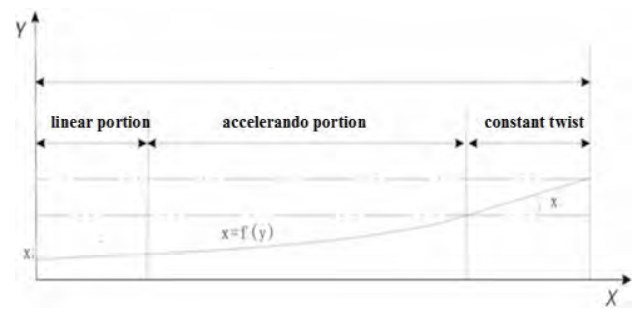

Figure 2 .

The sketch map of cathode movement.

So that:

$$
B_{\mathrm{c}}=L_{\mathrm{c}} \tan \left(\varphi_{1}+\theta\right)+L_{\mathrm{c}} \tan \left(\varphi_{1}-\theta\right)+b_{\mathrm{c}}
$$

in such a machining moment, we can get:

$$
B_{\mathrm{x}}=b_{\mathrm{c}}+L_{\mathrm{c}} \tan \varphi-L_{\mathrm{c}} \tan \varphi_{0}+2 \Delta_{\mathrm{c}}
$$

In order to calculate and modeling conveniently, we ignore the $\Delta_{\mathrm{c}}, \Delta_{0}$ for the moment, so that:

$$
\Delta_{\mathrm{B}}=L_{\mathrm{c}} \tan \varphi-L_{\mathrm{c}} \tan \varphi_{0}
$$

Secondly, to improve the efficiency of production, we set up the relation between $L_{\mathrm{c}} 、 \theta$ and current $I$ :

when machining, workpiece volume was wipe off by the whole cathode tooth, the volume can be calculated from the following equation:

$$
V=\int_{0}^{L_{c}}\left[x \tan \left(\varphi_{1}+\theta\right)+x \tan \left(\varphi_{1}-\theta\right)+b_{\mathrm{c}}\right] x \tan \alpha d x
$$

If the current density was confirmed, the $L_{\mathrm{c}}$ is more longer, the $I$ is more greater, so the productivity can be improved, so that:

$$
I=i \cdot \frac{B_{\mathrm{c}}+b_{\mathrm{c}}}{2} \cdot L_{\mathrm{c}}
$$

We put Equation 6 into Equation 10:

$$
I=i L_{\mathrm{c}} b_{\mathrm{c}}+\frac{i}{2} L_{\mathrm{c}}^{2}\left[\tan \left(\varphi_{1}+\theta\right)+\tan \left(\varphi_{1}-\theta\right)\right]
$$


Last, we can boil the problem down to: what are $L_{\mathrm{c}}$ and $\theta$, can make the $\Delta B$ as small as possible and make sure the $I$ as big as possible:

That is $\frac{d I}{d x}=0, \frac{d B_{\mathrm{c}}}{d x}=0$, then calculate the $L_{\mathrm{c}}, \theta$. So we can confirm the parameters.

\section{SiMULATION PROCESS}

After setting up the mathematical model, we build the entity model of cathode teeth to optimize the parameters. In order to simplify the entity model to simulate the machining process, a single tooth model was got, which is demonstrated in Fig .3.

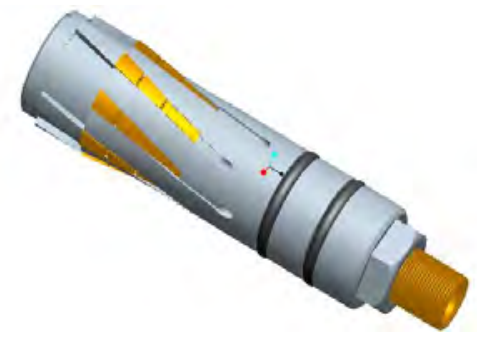

Figure 3.

The cathode design model.

Using the software, the theory model of gun tube rifle was shown in Fig .4. The important parameters are: the length of the gun tube is $1900 \mathrm{~mm}$, the inside diameter is $30 \mathrm{~mm}$, the external diameter is $60 \mathrm{~mm}$.

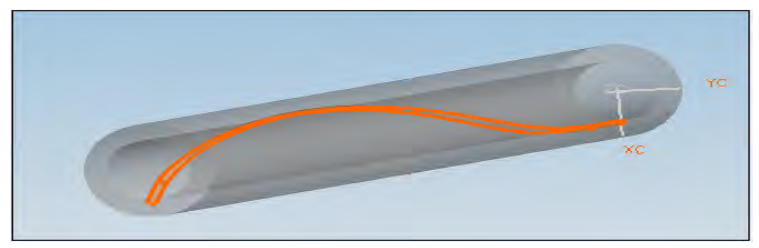

Figure 4.

The theory model of gun tube rifle.

The simulation control program can be seen in Fig .5. Then we can get the machining model after the simulation was end up. The cannon pipe is opacity.

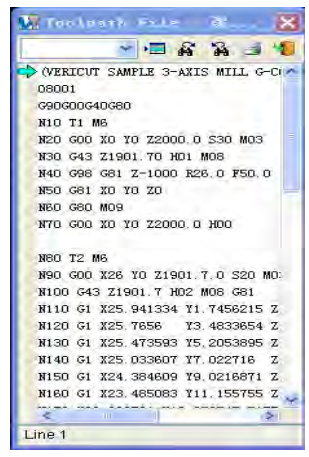

Figure 5.

The simulation control program.

\section{EXPERIMENTAL SETUP AND PROCEDURE}

In order to optimize the output electrochemical machining parameters, the input parameters selection on the one hand and the design with good isolation of the tool on the other hand are very important. The accuracy of the tool design and manufacturing systems are very important. It is attempted to select the input parameters of the system so that the machining time is minimized. In this case some tool parameters such as its effective length and also its gap with the inner surface of the pipe are determined. In the practical step, according to the desired clearance between the tool and the pipe in rifling operations, some other tool parameters such as geometrical positioning are also defined. The main brass body of the tool is shown in Fig .6. The main brass body and isolated parts are prepared after various machining operations. Electrolyte can pass through the center line axis of the tool and reach the machining gap via some holes which are provided on the rear of the tool's tail.

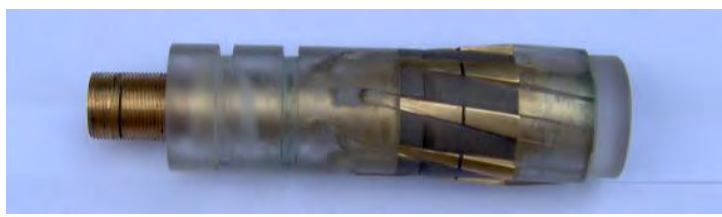

Figure 6.

The electrochemical cathode body.

In order to get the eligible parameters, tests are carried out on horizontal CNC-ECM machine equipped with 1000A, which is shown in Fig .7. An aqueous solution of $\mathrm{NaCl}$ is used as electrolyte. The basic testing parameters are shown in Table 1.

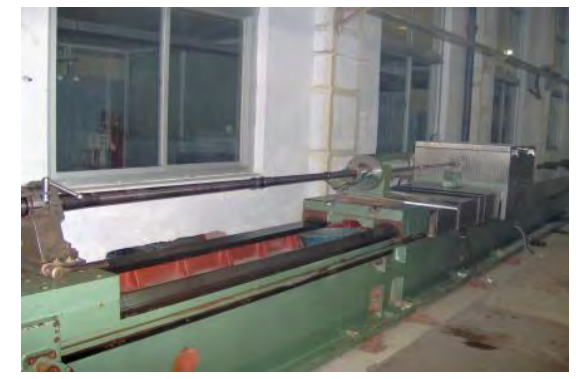

Figure 7.

CNC-ECM machine tool.

TABLE I. THE PARAMETERS IN MACHINING PROCESS

\begin{tabular}{|c|c|c|}
\hline Items & \multicolumn{2}{|c|}{ Description } \\
\hline Mean diameter of tool & \multicolumn{2}{|c|}{$30.04 \mathrm{~mm}$} \\
\hline Initial diameter of pipe & \multicolumn{2}{|c|}{$29.92 \mathrm{~mm}$} \\
\hline Voltage & \multicolumn{2}{|c|}{$10 \mathrm{~V}$} \\
\hline Tool material & \multicolumn{2}{|c|}{ Brass } \\
\hline Work piece material & \multicolumn{2}{|c|}{ W907Ni } \\
\hline \multirow{4}{*}{ Electrolyte } & Material & Nacl \\
\hline & Concentration & $11 \% \mathrm{NaCl}$ \\
\hline & Temperature & $35^{\circ} \mathrm{C}$ \\
\hline & Preasure & $2.5 \mathrm{MPa}$ \\
\hline velocity & Velocity & $10 \mathrm{~mm} / \mathrm{min}$ \\
\hline
\end{tabular}

The electrolyte pump and the electrolyte pool are disposable out of the door, and the pipeline is introduced to the machining area. The control tank is installed independently, which can make the control signal undisturbed. The material of haul pole is brass, which was driven by the driven box. The former water jacket is to 
envelop the electrolyte. The cannon pipe is fixed between two chucks. The transmit electricity block is to make copper with good electrical conductivity. A high pressurized electrolyte is pumped between the gap of the tool and the workpiece during machining operation. An aqueous solution of $\mathrm{NaCl}$ is used as electrolyte.. The $\mathrm{CNC}$ machining procedure and the receding procedure are seen in Fig .8.

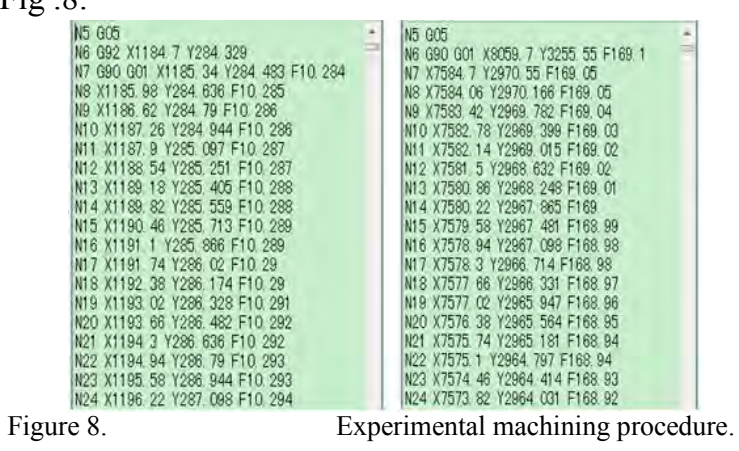
Fig .9.

The eligible gun tube rifle and the slice up are shown in

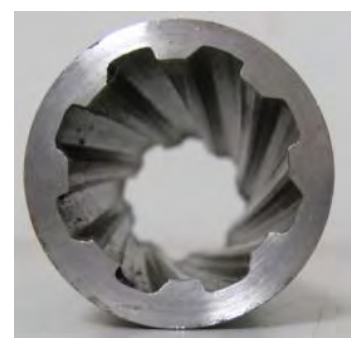

Figure 9

The machined gun tube rifle.

\section{CONCLUSIONS}

It is demonstrated that the computer-aided design for tool cathode feed from three sides and simulation of machining can improve the design precision of cathode, reduce the experimental efforts, and shorten the cathode design cycle, thus avoiding the costly trial and error tool design for any new applications. Additional developments are needed to further extend the possibilities of the electrode shape change algorithms and in future work the electrochemical models can be improved.

\section{ACKNOWLEDGMENTS}

This research work was supported by National Natural Science Foundation of China (Grant No. 51405365), Shaanxi Key Laboratory of Non-Traditional Machining Science and Research Program (Grant No. 14JS032), Project supported by Science and Technology Department of Shaanxi Province (2014JM7253), and open fund supported by Jiangsu Key Laboratory of Digital Electrochemical Machining (Changzhou Institute of Technology) (Grant No. KFJJ2004009).

\section{REFERENCES}

[1] S.D. Dhobe, B. Doloi and B. Bhattacharyya, "Surface Characteristics of ECMed Ttitanium Work Samples for Biomedical Applications". International Journal of Advanced Manufacturing Technology, vol. 55, Dec. 2011, pp. 177-188 , doi:10.1007/s00170-010-3040-5.
[2] M. Burger, L. Koll, E.A. Werner, and A. Platz, "Electrochemical Machining Characteristics and Resulting Surface Quality of the Nickel-base Single-crystalline Material LEK94," Journal of Manufacturing Processes, vol. 14, Jan. 2012, pp.62-70, doi:10.1016/j.jmapro.2011.08.001.

[3] D. Zhu, D. Zhu, and Z. Xu, "Optimal Design of the Sheet Cathode using W-shaped Electrolyte Flow Mode in ECM," International Journal of Advanced Manufacturing Technology, vol. 62, Jun. 2012, pp147-156.

[4] P. Asokan, R.R. Kumar, R. Jeyapaul, and M. Santhi, "Development of Multi-objective Optimization Models for Electrochemical Machining Process," International Journal of Advanced Manufacturing Technology, vol. 39, Jul. 2008, pp55-63.

[5] R. Mukherjee and S. Chakraborty, "Selection of the Optimal Electrochemical Machining Process Parameters Using Biogeography-based Optimization Algorithm," International Journal of Advanced Manufacturing Technology, vol. 64, Mar. 2013, pp.781-791.

[6] S. Ramarao and G. Padmanabhan, "Linear Modeling of the Electrochemical Machining Process Using Full Factorial Design of Experiments," Journal of Advanced Mechanical Engineering, vol. 1, Feb. 2013, pp.13-23, doi:10.7726/jame.2013.1002.

[7] Y. Lu, K. Liu, and D. Zhao, "Experimental Investigation on Monitoring Interelectrode Gap of ECM with Six-axis Force Sensor," International Journal of Advanced Manufacturing Technology, vol. 55, Jun. 2011, pp.565-572.

[8] M.H. Wang and D. Zhu, "Fabrication of Multiple Electrodes and Their Application for Micro-holes Array in ECM," International Journal of Advanced Manufacturing Technology, vol. 41, Mar 2009 , pp. $42-47$.

[9] J. Kozak, M. Chuchro, A. Ruszaj, and K. Karbowski, "The Computer Aided Simulation of Electrochemical Process with Universal Spherical Electrodes when Machining Sculptured Surfaces," Journal of Materials Processing Technology, vol. 107, Sep. 2000, pp.283-287.

[10] T. Paczkowski and J. Sawicki, "Electrochemical Machining of Curvilinear Surfaces," Machining Science and Technology, vol. 12, Sep. 2008, pp. 33-52.

[11] D. Zhu, D. Zhu, Z.Y. Xu, Q. Xu, and J. Liu, "Investigation on the Flow Field of W-shape Electrolyte Flow Mode in Electrochemical Machining," Journal of applied electrochemistry, vol. 40, Oct. 2010, pp. 525-532.

[12] M.S. Hewidy, S.J. Ebeid, T.A. El-Taweel, and A.H. Youssef, "Modelling the Performance of ECM assisted by Low Frequency Vibrations," Journal of Materials Processing Technology, vol. 189, Sep. 2007, pp.466-472.

[13] S. Van Damme, G. Nelissen, B. Van Den Bossche, and J. Deconinck, "Numerical Model for Predicting the Efficiency Behaviour During Pulsed Electrochemical Machining of Steel in $\mathrm{NaNO}_{3}$," Journal of applied electrochemistry, vol. 36, Nov. 2006, pp.1-10.

[14] J.W. Xu, N.Z. Yun, Y.X. Tang, and K.P. Rajurkar, "The Modelling of NC-electrochemical Contour Evolution Machining Using a Rotary Tool-cathode," Journal of Materials Processing Technology, vol. 159, Feb. 2005, pp. 272-277.

[15] M. Purcar, A. Dorochenko, L. Bortels, J. Deconinck, and B. Van den Bossche, "Advanced CAD Integrated Approach for 3D Electrochemical Machining Simulations," Journal of Materials Processing Technology, vol. 203, Feb. 2008, pp. 58-71.

[16] J. Pattavanitch, S. Hinduja, and J. Atkinson, "Modelling of the Electrochemical Machining process by the Boundary Element Method," CIRP Annals-Manufacturing Technology, vol. 59, Dec. 2010, pp. 243-246.

[17] M.H. Wang and D. Zhu, "Simulation of Fabrication for Gas Turbine Blade Turbulated Cooling Hole in ECM based on FEM," Journal of Materials Processing Technology, vol. 209, May. 2009, pp. 1747-1751.

[18] R. Mahdavinejad and M. Hatami, "On the Application of Electrochemical Machining for Inner Surface Polishing of Gun Barrel Chamber," Journal of Materials Processing Technology, vol. 202, Sep. 2008, pp. 307-315. 